\title{
OS CONDENADOS À CULPA EM “AS AFINIDADES ELETIVAS” DE GOETHE
}

Antonio Henrique Pires dos Santos

\begin{abstract}
RESUMO
Este trabalho analisa a noção de culpa no romance As Afinidades Eletivas, escrito por Goethe, e como ela serve de elemento originário para o direito. No romance, a ideia de uma consciência iluminada e livre e a esperança de que ela garantirá o progresso e a felicidade termina por tornar as personagens cegas diante da situação crítica em que vivem. O direito, por sua vez, no auge de sua formação, considera ter dominado a força dos acontecimentos, ainda que suas declarações sejam impotentes para decidir de uma vez por todas sobre suas guerras. Como tudo já está resolvido no plano teórico, nenhum acontecimento traz a crítica, mas suscita apenas a culpa. As tragédias do cotidiano são, assim, neutralizadas, e o sofrimento das vítimas é relativizado. Em primeiro lugar, problematizamos os conceitos de escolha e decisão e a tensão que há entre eles no romance de Goethe. Ainda, analisamos Mittler, a voz da moral e dos bons costumes, e seu papel na manutenção do clima de hesitação que ronda o romance. A partir disso, investigamos o papel da culpa no direito e sua ligação com o destino que arrasta a sociedade na manutenção de um ciclo de violência. Ressaltamos, por fim, que a tarefa do crítico se impõe como uma atitude perante a catástrofe que, ao invés de relativizá-la e naturalizá-la, visa à interrupção do ciclo de violência, impedindo sua repetição e fazendo emergir novas formas de vida.
\end{abstract}

Palavras-chave: Culpa. Violência. Direito. Mito. Destino.

\section{THE CONDEMNED TO GUILT IN GOETHE'S ELECTIVE AFFINITIES}

\begin{abstract}
This paper analyzes the notion of guilt in the novel Elective Affinities, written by Goethe, and how it serves as the originating element to the law. In the novel, the idea of an enlightened and free conscience, and the hope that it will ensure the progress and happiness, ends up by turning the characters blind about the critical situation in which they live. The law, for its turn, at the height of its formation, considered to have mastered the force of events, although his declarations are powerless to decide once and for all about its wars. As everything is already solved in theory, no event brings criticism, but only brings guilt. The daily tragedies are thus neutralized, and the suffering of the victims is relativized. First, we question the concepts of choice and decision and the tension that exists between them in Goethe's novel. Still, we


analyze Mittler, the voice of morality and good manners, and its role in maintaining the hesitation climate that surrounds the novel. From this, we investigate the role of guilt in the law and its connection with the destiny that drags society in maintaining a cycle of violence. We emphasize, finally, that the critic's task is imposed as an attitude towards catastrophe, rather than relativize it and naturalize it, aims to break the cycle of violence, preventing its repetition and giving rise to new forms of life.

Keywords: Guilt. Violence. Law. Myth. Destiny.

\section{Introdução}

Este trabalho analisa a noção de culpa no romance "As afinidades eletivas", de Goethe, e como ela serve de elemento originário para o direito, mantendo os indivíduos presos às escolhas sobre o que já está posto. Principalmente em um tempo que suscita o fim da história, as declarações de direitos são valiosos monumentos erigidos para expressar uma promessa aparentemente já resolvida. Nesse sentido, não haveria mais que decidir sobre a instauração de novos modos de tratar os problemas da sociedade, mas simplesmente escolher entre os instrumentos apresentados pelo direito, corrigindo eventuais usos arbitrários.

Diante disso, é preciso questionar o modo de interpretar as mortes decorrentes das ações drásticas do Estado. Seriam elas o preço a se pagar pela realização do direito no mundo fático ou expressão de uma catástrofe anunciada? No romance de Goethe, as personagens, ao arrogarem para si um suposto esclarecimento, terminam por negligenciar o instante crítico em que se encontram. A ideia consagrada de uma consciência iluminada e livre e a esperança de que ela garantirá o progresso e a felicidade termina por torna-los cegos diante da situação em que vivem.

No contexto do direito, sua violência mítica faz com que passado, presente e futuro sejam enclausurados; o que foi posto na origem bloqueia qualquer acontecimento novo; o que foi dito fecha as portas para um novo dizer. $\mathrm{Na}$ atividade do jurista, o ato de conhecimento se reduz ao critério de adequação. O caráter ficcional deste ato tem como consequência um emudecimento: não há mais nada 
para se dizer, todos os acontecimentos devem ser reconduzidos ao seio da lei. É justamente essa hesitação e esse silêncio que percorrem a obra "As afinidades eletivas", levando à morte de Ottilie. Segundo Benjamin, tratando das personagens do romance:

Elas, porém, submetem-se no auge de sua formação cultural a forças que
essa formação considera dominadas, por mais que a cada vez se mostre
impotente para subjugá-las. Essas forças deram aos seres humanos o
senso para o que é conveniente; já para o que é moral, eles o perderam.
Não se trata aqui de um julgamento de sua ação, mas um julgamento de
sua linguagem. Pois eles seguem seu caminho sentindo, porém surdos;
enxergando, porém mudos. Surdos perante Deus e mudos diante do
mundo. Ao prestarem contas fracassam, não pelo seu agir, mas sim pelo
seu existir. Eles emudecem. (BENJAMIN, 2009, p. 26)

A posição do crítico reside no reconhecimento da distância entre o texto e o presente, reconhecendo o tempo atual enquanto tempo histórico. No auge de sua formação, o direito considera ter dominado a força dos acontecimentos, ainda que suas declarações sejam impotentes para decidir de uma vez por todas sobre suas guerras. Os fenômenos que Ihe excedem são traduzidos como déficit democrático ou disfunções ocasionais, nunca como expressão imediata da própria forma do direito. Para o crítico, no entanto, a apreciação do fenômeno extremo suscita a possibilidade de quebrar os limites da experiência.

É na catástrofe, nas cinzas do fogo consumido, que a crítica tem lugar enquanto tarefa alquímica e onde o mito se evidencia. O processo de decomposição do casamento em "As afinidades eletivas" expõe as forças mágicas do mito que ainda vigoram na sociedade feudal (CASTRO, 2011, 90). No mundo do direito, as tragédias do cotidiano são cada vez mais frequentes, mas elas não são conectadas de forma alguma com o pensamento jurídico da época. Este levaria apenas ao progresso, sendo a catástrofe um mero desvio, um mal necessário, uma deturpação de toda ordem. Nesse sentido, qualquer medida drástica, qualquer excesso cometido pelo Estado é entendido como a uma última medida drástica para alcançarmos o reino dos direitos. A catástrofe, então, é reconduzida à linguagem da lei, permitindo a repetição do mesmo e conservando sua violência mítica. Para Benjamin, em sua obra Escritos sobre mito e linguagem, este tipo de violência é aquela que instaura direito, sendo o estabelecimento de fronteiras o fenômeno 
originário. O mito instaura o conhecimento sobre o bem e o mal e impõe um destino àquele que transgride suas fronteiras. O direito, enquanto imperativo, já traz o conhecimento sobre o bem e o mal de antemão: é considerado bom aquilo que está de acordo com o dever, e mal aquilo que se desvia dele. Como tudo já está resolvido no plano teórico, faltando apenas sua aplicação; como a tomada de consciência supostamente já ocorreu, nenhum acontecimento traz a crítica, mas suscita apenas a culpa. A catástrofe não nos faz refletir sobre suas causas, sobre quais erros cometemos, mas nos traz a pergunta sobre quem é o culpado, ou seja, remete ao par conceitual caráter-destino:

Diante do direito ou do mito, a vida é culpa, um débito que não se pode pagar. O domínio do mito é aquele do débito impagável, que permanece impagável na medida em que a criatura acredita saldá-lo conservando a simples vida, que é sempre testemunha desta dívida. Esta é também a natureza do direito racional, que, ao reivindicar a universalidade e a igualdade, não esconde a sua natureza violenta, autoritária, e jamais pode se confundir com a verdadeira justiça. (CASTRO, 2011, p. 103)

A verdadeira experiência da história, segundo Benjamin, no sentido de Erfahrung, é a experiência filosófica de redenção: perdão do débito e destruição do mito, como observa Claudia Castro em sua obra $A$ alquimia da crítica. $O$ momento de decisão que se ergue do domínio da mera vida também interrompe o eterno retorno do mesmo. A destruição do mito de que fala Benjamin não suscita um tempo de paz ou o fim da história, mas a possibilidade da crítica:

Assim se define a tarefa da crítica: encarregar-se desse legado histórico visando à abolição do mito. Seja ele um texto ou uma configuração social, caberá ao crítico, filósofo, em seu trabalho incansável de alquimista, trazer à luz o conteúdo de verdade dos fenômenos históricos, que pode ser lido como um pedido de redenção. (CASTRO, 2011, p. 112-113)

Sem a tarefa do crítico, não poderemos vislumbrar a efetivação de direitos a partir de um ponto de vista ético, mas sempre a partir da submissão muda à sua lei. Segundo Benjamin, o direito não visa à punição de um indivíduo desviado, mas tanto o mito quanto o direito criam a culpa para poder punir e manifestar assim sua própria força (Gewalt).

A perpetuação de uma época em que a suspensão de direitos se tornou regra é o exemplo de como a redução do debate sobre a criação de condições mínimas de 
dignidade para os indivíduos a uma mera questão de aplicação de institutos jurídicos produz a eterna repetição da violência sobre as vítimas. A partir disso, impõe-se pensar o direito enquanto uma tarefa interminável, a partir da destruição de suas experiências já cristalizadas, abrindo espaços para a oportunidade de uma experiência do real que implique um novo conhecimento, ao invés de um simples julgamento de adequação. Este artigo pretende analisar o romance "As afinidades eletivas", a fim de expor os elementos que arrastam a história para seu fim trágico e sua relação com o mundo do direito.

Em primeiro lugar, problematizaremos os conceitos de escolha e decisão e a tensão que há entre eles no romance de Goethe, tendo como pano de fundo o casamento entre Eduard e Charlotte e sua natureza ambígua, sendo ao mesmo tempo o símbolo do "ápice da cultura" e o vínculo mítico que impõe a culpa e impede qualquer decisão. Ainda, vamos nos deter em Mittler, a voz da moral e dos bons costumes, e analisar seu papel na manutenção do clima de hesitação que ronda o romance, fazendo com que as demais sejam arrastadas pelas forças do mito rumo ao seu fim trágico. A partir disso, analisaremos o papel da culpa no direito e sua ligação com o destino que arrasta a sociedade na manutenção de um ciclo de violência.

\section{Escolha e decisão em "as afinidades eletivas"}

O romance apresenta uma contaminação entre as forças da natureza, as forças do mito, e a suposta liberdade da razão. A relação entre Eduard e Charlotte possui uma natureza ambígua: apesar de se apresentarem como esclarecidos, são incapazes de tomar uma decisão sobre os problemas que os cercam, sendo tragados pelas forças naturais, justamente aquelas das quais a razão teria se libertado. O casamento, neste contexto, apesar de descrito como o ápice da cultura, traz no seu aspecto jurídico não a liberação das relações éticas, mas sua clausura, expressa na demonização do divórcio. Vamos analisar a relação entre Charlotte e Eduard a partir do simbolismo do casamento enquanto vínculo jurídico e seu impacto nas relações concretas, refletidas na indecisão e na renúncia que transpassa as personagens. 
A história começa apresentando Eduard e Charlotte. Eles eram apaixonados na juventude, mas aquele acaba se casando com uma mulher mais velha que the oferecia um casamento mais vantajoso. Após a morte desta, Eduard e Charlotte finalmente se casam e decidem viver em um ambiente afastado da cidade. Após dois anos de tranquilidade, eles abrem as portas para dois hóspedes: o Capitão, amigo de Eduard, que se encontra desamparado, e Ottilie, sobrinha e filha adotiva de Charlotte. Durante a narrativa, as personagens se dedicam exclusivamente a atividades lúdicas, como a música e a representação de quadros famosos, sendo a mais importante a reforma dos jardins do castelo, que suscita diálogos em que o silêncio, a polidez e a dissimulação sobrepujam a possibilidade de um discurso claro e elaborado.

No contexto do romance, "afinidades eletivas" se referem a fenômenos químicos de separação e atração. Apesar de serem um fenômeno da natureza, as personagens Eduard, Charlotte e o Capitão acabam interpretando sua situação à luz dessa teoria:

\begin{abstract}
Até vermos tudo isso com os próprios olhos, vamos considerar essa fórmula como uma alegoria, da qual podemos tirar ensinamentos para uso imediato. Você, Charlotte, representa o $A$, e eu o seu $B$, visto que na verdade estou ligado a você e a sigo como o B ao A. O C é evidentemente o Capitão, que agora está de certo modo me afastando de você. Bem, para que não fique na incerteza, é justo que se procure um D para você, esse será sem dúvida a amável senhorita Ottilie, cuja vinda você não pode mais protelar. (GOETHE, 2008, 47)
\end{abstract}

Ocorre, no entanto, que apesar da maneira altiva de Eduard, sua previsão falha, ocorrendo na verdade uma aproximação entre ele e Ottilie e entre Charlotte e o Capitão. A ideia de ter dominado as forças da natureza acaba por engendrá-los em uma crise sem saída. A força dessas atrações os leva a tomar resoluções que nunca resolvem os conflitos. Esse caráter dúbio da liberdade pode ser explicitado se distinguirmos escolha e decisão. A escolha é feita a partir de opções já postas, enquanto que a decisão se liberta dos limites e inaugura o estado de coisas em que essas opções se tornam possíveis:

Trabalhando com uma sutil mas importante distinção entre "escolha" (em alemão Wahl, que consta no título do romance) e "decisão" (em alemão Entscheidung), Benjamin argumenta que o romance tenta criar um mundo

Mestrando pelo Programa de Pós-Graduação em Ciência Política da Universidade Federal de Pernambuco (UFPE). Brasileiro, residente em Recife - PE, E-mail: antonio.hps26@gmail.com 
fictício em que as meras escolhas substituem, no reino ético, as decisões, que propriamente ali pertencem. Nos termos da distinção de Benjamin, a escolha pertence ao reino mítico e natural das ambiguidades crepusculares, um reino de sacrifício sem redenção ${ }^{1}$. (LEACOCK, 2002, p. 282-283) (Tradução nossa)

No contexto do romance, a concepção de casamento possui uma série de qualidades que não são passíveis de serem postas em crise, valendo como pressuposto e conduzindo as ações das personagens:

\begin{abstract}
Quem ultraja o matrimônio - exclamou ele [Mittler] -; quem com palavras ou ações mina essa base de todos os valores morais vai se ver comigo; e, se eu não posso guiá-lo, também não quero saber dele. $O$ casamento é o princípio e o ápice de toda a cultura. Ele torna afável a pessoa rude, e a mais educada tem melhores oportunidades para demonstrar a sua afabilidade. Ele deve ser indissolúvel, pois traz tanta felicidade, que qualquer infortúnio isolado não tem nenhum valor diante dele. E para que falar em desgraças? É a impaciência que assalta o homem de tempos em tempos, e ele então tende a sentir-se infeliz. Deixem passar esse momento, e sentir-se-ão felizes por algo, há tanto tempo mantido, continuar existindo. Nunca haverá motivo suficiente para a separação. A condição humana é tão repleta de sofrimentos e alegrias, que não se pode calcular num casal o quanto um deve ao outro. É uma dívida infindável, que só pode ser saldada pela eternidade. Às vezes pode ser incômodo, bem o sei, e isso é até bom. Não estamos casados com a nossa consciência também? $\mathrm{E}$ muitas vezes não gostaríamos de nos livrar dela, já que ela é mais incômoda do que qualquer marido ou esposa? (GOETHE, 2008, 71) (grifo nosso)
\end{abstract}

Representante da força mítica do casamento, Mittler faz a mediação entre as quatro personagens. Na verdade, ele nunca fala em seu nome, mas permanece como a voz da lei, das forças míticas que prendem as personagens na nulidade da escolha. Seu caráter é refletido pela sua função, expressa no seu próprio nome, que significa mediador ${ }^{2}$. Ele havia sido um eclesiástico empenhado na tarefa de apaziguar todas as desavenças, e diz-se que enquanto estava neste posto, nenhum casal se separou. Note-se que, na sua defesa do casamento, este não deve ser

\footnotetext{
1 ('Working with a subtle but significant distinction between 'choice' (the German Wahl of the novel's title) and 'decision' (the German Entscheidung), Benjamin argues that the novel attempts to create a fictional world in which mere choices substitute in the ethical realm for the decisions that properly belong there. In the terms of Benjamin's distinction, choice belongs to a natural-mythical realm of twilight ambiguities, a realm of sacrifice without redemption. Decision, in contrast, brings clarity in an ethical realm determined by the possibility of transcendence") LEACOCK, N. K. Character, silence and the novel: Walter Benjamin on Goethe's Elective Affinities. Narrative, Volume 10, Number 3, 2002. p. 282-283.

2 "A palavra alemã Mitller significa "mediador". Mas no adjetivo Mittell ressoa também a conotação do mediano, do medíocre e do vulgar". GOETHE, Johann Wolfgang Von. As afinidades eletivas. São Paulo: Nova Alexandria, 2008. Nota do tradutor. p. 31.
}

Mestrando pelo Programa de Pós-Graduação em Ciência Política da Universidade Federal de Pernambuco (UFPE). Brasileiro, residente em Recife - PE, E-mail: antonio.hps26@gmail.com 
mantido simplesmente pelas vontades dos indivíduos, mas constitui em si mesmo uma vantagem. A vontade é anulada ainda no aprisionamento do casamento em uma dívida infindável entre os cônjuges. O vínculo criado pelo direito não pode, pois, ser desfeito, pois uma tal dívida só pode ser saldada pela eternidade. Vale lembrar que a palavra dívida, destacada no trecho acima, é uma tradução do alemão Schuld, palavra que, por uma "ambivalência demoníaca" (BENJAMIN, 2012, 37), significa também culpa.

Mittler, ao longo da narrativa, permanece um elemento distante, chamado até mesmo de estranho, sem conseguir articular um diálogo produtivo com as demais personagens, mas expressando sempre a interdição e o julgamento. É a partir dessa concepção que o casamento não pode ser questionado, e mesmo Mittler não consegue transmitir a Charlotte o pedido de divórcio, quando requisitado por Eduard. Ainda que a presença de Mittler não seja tão frequente, suas falas vazias e inconvenientes, expressão de um senso comum medíocre, são impactantes na narrativa e representam a voz da lei que permanece na mente das personagens, principalmente na de Charlotte e do Capitão, como uma autoridade internalizada, impondo a culpa e fazendo vencer a hesitação e a renúncia.

$\mathrm{Na}$ primeira parte do romance, essa renúncia aparece no constante adiamento das resoluções. O Capitão e Charlotte, apesar de preverem maus agouros, são incapazes de impedir os ímpetos de Eduard. Charlotte, logo no início da narrativa, mesmo avisando a Eduard que a chegada de terceiros pode desestabilizar uma situação equilibrada, no caso, o relacionamento deles, este simplesmente responde que tais estímulos obscuros não afetam pessoas esclarecidas: "Isso bem pode acontecer - replicou Eduard - com pessoas que vivem somente para si, no escuro, mas não com aquelas mais conscientes, já esclarecidas pela experiência" (GOETHE, 2008, 25). Sobre as reformas no jardim, Eduard passa por cima dos planejamentos de Charlotte, mesmo com as ponderações do Capitão. Entretanto, Charlotte não consegue expressar abertamente seu descontentamento, restando apenas uma inquietação muda após cada conversa que trava com Eduard. No aniversário de Charlotte, quando um menino quase se afoga no lago devido às 
intervenções mal feitas por Eduard nas terras da margem, o Capitão já havia previsto que tais mudanças eram descabidas, mas seu bom senso e sua condição de hóspede o impedem de interpelar Eduard.

Durante toda a primeira parte, prevalecem a dissimulação, o adiamento e o silêncio do decoro. Não apenas com relação à reforma do jardim, mas mesmo a aproximação entre Charlotte e o Capitão e Ottilie e Eduard se intensificam sem que ninguém possa fazer nada. Se o segundo par se deixa constituir livremente, o primeiro, marcado pela racionalidade de Charlotte e do Capitão, percebe que há algo de errado:

O Capitão já começava a sentir que um hábito irresistível ameaçava prendêlo a Charlotte. Teve forças para se esquivar nos momentos em que Charlotte costumava ir às plantações; levantava-se mais cedo, punha tudo em ordem, recolhendo-se, então, à sua ala do castelo para trabalhar. Nos primeiros dias, Charlotte considerou aquilo uma casualidade e procurou-o em todos os lugares prováveis; depois começou a compreendê-lo e estimou-o ainda mais por isso. (GOETHE, 2008, 64)

Há uma diferença no modo como os dois pares reagem à força das afinidades eletivas. Ottilie e Eduard se entregam um ao outro sem pensar nas consequências. O Capitão e Charlotte, por outro lado, têm consciência da atração e de que esta não deve ser estimulada. Ainda assim, os dois são arrastados junto com Ottilie e Eduard pelas forças da natureza que as convenções e as leis tentam reprimir, mas acabam reproduzindo. O Capitão e Charlotte têm internalizada a autoridade da lei, o que implica desejo reprimido e renúncia. Esses elementos, porém, apenas conseguem adiar a tragédia, sem resolver e decidir pela atração que já emergiu no ambiente das personagens. Essa aproximação tem como consequência um quase beijo, fazendo Charlotte desabar em culpa pelo que está sentindo. O que mais a caracteriza é o fato de que "não conseguia abandonar os antigos planos, nem rejeitar, de todo, os novos" (GOETHE, 2008, 37). Quando ao Capitão são oferecidas novas oportunidades de vida, inclusive um casamento vantajoso, Charlotte assume a renúncia pura e completa e resolve fazer com que Eduard perceba a gravidade da situação, clamando por uma saída:

Nos casos mais graves, deve agir e ajudar aquele que estiver vendo com maior clareza. Desta vez sou eu. Querido, meu querido Eduard, deixe-me 
agir! Você será capaz de exigir que eu renuncie à felicidade já conquistada e aos meus mais justos direitos sobre você? (GOETHE, 2008, 99)

Aqui mostra-se claramente a submissão de Charlotte a Eduard. Ela pretende tomar uma decisão sobre o problema que está vivendo, mas não é realmente uma decisão. Ela tenta mandar Ottilie para o internato, de modo a conservar seu casamento com Eduard. Assim, escolhe-se entre as opções mais viáveis para proteger seus direitos sobre Eduard. O que ela não consegue enfrentar é o fato de que Eduard já foi arrematado por Ottilie e qualquer decisão que não se eleve sobre essa situação não conseguirá libera-la de seus tormentos. Aqui estão duas atitudes frequentes no romance: renúncia e adiamento. Charlotte vê-se frequentemente entre a vontade de conservar os antigos feitos e de permitir a vinda de novos acontecimentos. Apesar de o narrador dizer que ela age de maneira resoluta, Charlotte prende-se ao constante adiamento dos conflitos, e mesmo quando confronta Eduard, vê-se submissa aos seus ímpetos. Essa atitude reativa também é tomada por Eduard, que não expõe de maneira clara seus sentimentos por Ottilie, mas apenas se deixa arrastar pelos seus sentimentos e dissimulando perante os demais. Quando Charlotte sugere enviar Ottilie ao internato, Eduard simplesmente tenta afastar esse ato, retirando-se da casa para que Ottilie permaneça. A violência mítica funciona como uma interdição constante, levando à indecisão. As personagens não são capazes de serem verdadeiramente resolutas, mas apenas se desviam do conflito. $\mathrm{Na}$ impossibilidade de colocar em crise o casamento e de enfrentar sua degradação, as personagens constantemente preferem se desviar dos problemas, procurando soluções que não resolvem efetivamente, mas apenas jogam para o futuro a possibilidade de sair da situação em que vivem. $O$ conflito não se resolve, mas é sempre suspenso, levando as personagens a caminhos até mais perigosos e com resultados mais danosos.

A primeira tragédia é a morte de Otto, filho de Charlotte e Eduard, concebido a partir de um duplo adultério fantasmático. A criança era o último fator que poderia fazer com que Eduard retornasse a Charlotte, e a gravidez foi inclusive festejada por Mittler, justo no momento em que este não sabia como reagir à ideia de Eduard em 
propor o divórcio. Acontece que Charlotte se sente culpada e resolve consentir no divorcio:

Consinto no divórcio. Devia ter-me resolvido há mais tempo; por minhas
hesitações, minha relutância, matei esta criança. Há certas coisas que o
destino assume com obstinação. Foi em vão que a razão e a virtude, o
dever e tudo o que há de sagrado se interpôs em seu caminho; tem de
acontecer aquilo que lhe parece justo e que a nós parece injusto; no final é
ele que se impõe, não importa o que façamos. Mas o que estou dizendo! Na
realidade, o destino pretende realizar os meus próprios desejos, os meus
próprios desígnios, contra os quais agi impensadamente. (GOETHE, 2008,
192)

Tal decisão, porém, não consegue liberar os vínculos jurídicos entre ela e Eduard, mas na verdade, o divórcio é deixado para que este e Mittler resolvam. $O$ Capitão, já promovido a Major, não consegue se condoer com a morte da criança, interpretando-a como um sacrifício necessário. A crença cega no destino leva a interpretar todos os acontecimentos trágicos de maneira relativizada. A morte da criança, ao invés de suscitar o luto, renova as velhas esperanças, sendo um mal necessário. Eduard, dominado pela necessidade de ficar com Ottilie, enxerga a morte como o fim de um obstáculo. Mittler, por sua vez, apesar de entender o quão crítica é a situação, confia sua resolução ao tempo.

Principalmente na parte final do romance, em que cada vez mais a situação vivida pelas personagens se mostra insustentável, uma série de resoluções é projetada sem, no entanto, viabilizarem nenhuma saída. A partir do capítulo 13, Eduard toma a decisão de ficar com Ottilie. Entretanto, esta "decisão" é sempre remetida à outra pessoa. Primeiro, ele pede a Ottilie, que diz que tudo depende de Charlotte. Após a morte da criança, Charlotte consente no divórcio, mas entrega sua concretização às mãos de Eduard, do Major e de Mittler. Da parte dela não haverá colaboração, considerações ou conselhos:

Diga a Eduard que consinto no divórcio, que entrego a ele, a você e ao
Mittler toda a resolução do assunto, pois pouco me importa a minha
situação futura e o que possa acontecer comigo. Assinarei todos os papéis
que me trouxerem, mas só não exijam a minha colaboração, as minhas
considerações, nem os meus conselhos. (GOETHE, 2008, 192-193)

Há ainda que notar a presença de Mittler no rol de pessoas que decidirão sobre o arranjo das quatro personagens. A decisão não se dá de maneira intensiva 
e, paradoxalmente, ela é tomada por todos e por ninguém. Ottilie também toma a decisão de renunciar a Eduard, mas mesmo essa decisão é tomada pela metade, pois, ouvindo uma conversa entre Charlotte e o Major sobre permitirem a união de Eduard e Ottilie, ela não se moveu para expressar seus sentimentos, fingindo que dormia. Inclusive, a decisão sobre o divórcio se desmancha a partir do momento em que Ottilie decide renunciar a Eduard. Após isso, ocorre o último esforço de Charlotte em conservar seu casamento, enviando Ottilie ao internato e, ainda no desejo de fazer com que tudo volte a ser como antes, arrumando os quartos do castelo da maneira como estavam mesmo antes da chegada do Capitão.

Todas as resoluções e as ditas decisões são direcionadas pelo sabor dos acontecimentos. Não surge nenhuma possibilidade nova frente aos impasses da situação atual. As personagens estão sempre andando em círculos, levados pela correnteza dos acontecimentos. Diante destes, escolhe-se o menor dos males possíveis. Nesse sentido, todo acontecimento ruim encadeado é um mal necessário, pois apenas a tragédia se anuncia e apenas possibilidades destrutivas são postas em jogo. A decisão seria propriamente quebrar esse ciclo, criando-se novas possibilidades de vida. Escolhas são sempre feitas, mas o problema permanece e continua a voltar em novas tragédias.

Todas essas voltas e reviravoltas, ímpetos e interrupções, soluções e frustrações têm seu fim com o silêncio de Ottilie, que resolve fazer um voto monástico. A situação das quatro personagens, no fim das contas, depende da decisão de Ottilie, que não expressa suas vontades, mas permanece carregada pelo destino e pela culpa. Ela decide não ir ao internato, não para impor sua vontade, mas simplesmente para aceitar as forças míticas do destino:

Queridos amigos, por que devo dizer expressamente o que já é óbvio? Desviei-me do meu caminho e não haverei de retomá-lo. Um demônio hostil está exercendo um poder sobre mim e de fora parece impedir-me até de encontrar harmonia comigo mesma. (GOETHE, 2008, p. 205)

A carta de Ottilie vem afirmar a impossibilidade de outro arranjo que não aquele já definido pelo mito e que qualquer tentativa de escapar ao destino é inútil. $A$ grande crise do romance é que, ainda que o casamento faticamente seja degradado 
pelas afinidades eletivas, ele ainda permanece enquanto símbolo, enquanto vínculo mítico do qual as personagens não podem escapar. A instauração do direito é também instauração de um destino, que se impõe de forma ambígua: se o casamento é o ápice da cultura, um dom do indivíduo civilizado, ele também se mostra como um limite. A transgressão daquilo que serve de paradigma, portanto, suscita a culpa. O burguês esclarecido, ao se deixar levar pelas paixões, elementos naturais que supunha ter dominado, sente-se culpado por não ser aquilo que deveria ser: racional e esclarecido. Se o casamento enquanto relação fática entre duas pessoas ruiu, ele permanece a assombrar as personagens enquanto símbolo, impondo a culpa pela transgressão. As personagens não conseguem se livrar dessa má consciência, mantendo-se na mudez, na hesitação e na renúncia, que ao invés de saldar sua dívida para com a lei, só a torna mais forte.

\section{Mittler: entre a culpa e hesitação}

É neste espaço da narrativa, em que toda expressão se cala, em que não há mais forças para nenhuma tentativa, que emerge a figura de Mittler. Vimos que seu senso comum rejeita tudo aquilo que é contrário à moral e aos bons costumes e que suas palavras, antes de estabelecerem uma comunicação produtiva, soam inoportunas e vazias. É significativo que a recepção do romance de Goethe, na época em que foi escrito, tinha como chave de leitura a defesa da concepção de casamento da qual Mittler é o porta-voz. Assim, a história seria um exemplo do que acontece com aqueles que transgridem as leis, e a morte de Ottilie e Eduard seria um aviso do que pode acontecer àqueles que se deixam levar pelos impulsos:

Na história da relação cruzada entre Eduardo e Otília e Carlota e o Capitão, a interpretação mais comum viu o triunfo da ordem social. O amor-paixão, a afinidade eletiva que enlaça os personagens, representaria o desejo subjetivo que, transgredindo a lei, se revela, no entanto, totalmente governado por ela, e justamente por causa dessa transgressão. Desta forma, Eduardo e Otília, o par central do romance, aquele que não conseguiu controlar a irresistível atração das afinidades, sucumbem arrastados pela corrente avassaladora de culpa e expiação. Tendo infringido a lei moral, os dois pagam a sua dívida com a morte da inocente criança, filho de Eduardo e Carlota, e com as próprias mortes, pois é apenas no sacrifício que encontram a purificação. Tal leitura equivocada, que orientou 
toda a filologia goethiana, segundo Benjamin, tomou as palavras proferidas pelo personagem Mittler em defesa do casamento, verdadeiro monumento ao lugar comum, como as próprias palavras de Goethe e a chave da interpretação de sua obra. (GOETHE, 2008, p. 85)

Assim, Mittler não apenas mantém as personagens na hesitação, mas é ele quem, ao enunciar as leis do casamento, suscita a culpa, para que as personagens não se esqueçam de seu débito perante a lei. No seu último discurso, suas ideias de mudança na redação dos dez mandamentos, para que sejam integralmente positivas, como em "honrarás pai e mãe", no sentido de aconselhar uma ação ao invés de proibir, não consegue evitar o nexo entre lei e crime, e mais ainda, não consegue evitar o nexo entre lei e culpa. Mittler pretende expurgar o crime e a falta mascarando a realidade, evitando que se saiba da possibilidade de viver fora da ordem e punindo secretamente aqueles que se desviam dela. Sua ideia era retirar os termos que instigassem o mal, como "matarás" ou "adultério". No entanto, o efeito imediato da lei que ele enuncia não é suscitar boas ou más condutas, mas a autoridade internalizada faz com que o desejo seja ele mesmo reprimido e torna a consciência culpada. A lei não é simplesmente um estímulo, mas já é uma sentença. Prova dessa falta de tato de Mittler é que quando ele diz "Não cometerás adultério!", Ottilie entra na sala, ouve aquelas palavras e segue para o quarto, onde morre de inanição. As palavras de Mittler, que no romance representa a voz da lei, são a sentença de Ottilie. Isso se deve ao fato de que suas palavras não prescrevem ações, mas são expressão de uma culpa originária.

Diante do que foi exposto, podemos começar a perceber a diferença entre escolha e decisão. As personagens não conseguem se elevar sobre as leis do destino que as consomem, pois estão limitadas às escolhas postas. Diante da sacralidade do casamento e das suas vantagens, desaparece sua natureza ética, enquanto decisão livre dos indivíduos de ficarem juntos. O ponto de partida é o simbolismo do casamento, que permanece como uma força exterior, um vínculo mítico impassível de ser colocado em crise. Com a degradação do casamento, então, o divórcio é palavra proibida e inaudita. Sobram apenas as escolhas decorrentes desse estado de coisas, que não é questionado. Assim, as personagens 
constantemente remetem a solução da crise às outras personagens e tentam se afastar até que tudo melhore e volte ao normal. No final das contas, todos compartilham de um tipo peculiar de culpa, pois ela não é atribuída por outro sujeito, mas pela autoridade internalizada que carregam, pela má consciência. As personagens compartilham, ao mesmo tempo, da liberdade e da interdição, do esclarecimento e da incapacidade de lidar com as forças do mito.

Vale ainda esclarecer que a indecisão tem um aspecto duplo. Não podemos dizer que ela é simplesmente algo de negativo, fadado a expressar apenas a omissão. Uma situação de indecisão faz com que surja um espaçamento entre o previsto e o desejado. Sem o momento de indecisão, decisão alguma pode ser tomada, devendo-se apenas deixar seguir o rumo natural (ou melhor, naturalizado) das coisas. O indecidível não apenas assombra a decisão já tomada, questionando sobre os outros rumos que poderiam ter surgido, mas também é o que torna possível qualquer decisão digna deste nome. Longe de dúvida e do autoquestionamento próprios da indecisão, não pode surgir decisão alguma. Assim, a renúncia também possui um aspecto duplo: pode ser a renúncia de decidir frente a uma indecisão, silenciando-se; pode ser a renúncia do autoquestionamento, de, frente a uma indecisão, reconduzi-la ao caminho seguro do já previamente decidido. No romance, ressalte-se o papel de Mittler, enquanto mediador, na conservação desse espaço cinzento de falso esclarecimento:

Foi necessária a insistência categórica desse homem, para afastar centenas de dúvidas, objeções, hesitações, indecisões, palpites, vacilações, opiniões, sugestões e reiterações, visto que habitualmente em tais ocasiões, de uma dúvida resolvida, sempre surgem outras novas, e, mesmo querendo respeitar todas as convenções, sempre ocorre 0 fato de se violarem algumas. (CASTRO, 2011, p. 161)

Mittler é quem esclarece. Ele é responsável por evitar que as pessoas se desviem do caminho, sanando quaisquer indecisões que possam suscitar caminhos diversos. É essa forma de apaziguamento que paralisa as personagens, deixandoas presas no futuro que o destino as reservou, no caminho iluminado da lei onde triunfam as forças do mito. A presença de Mittler é o ressoar de uma lei exterior, de uma voz sempre estranha para as personagens, que tem o efeito de reforçar os limites já postos por uma decisão de origem inacessível que inaugurou o estado de 
coisas vigente. Apaziguar e evitar os desvios é relembrar os limites do destino a que estão submetidas as personagens, da decisão que tem por efeito principal separar o possível do impossível. No romance, o divórcio é propriamente este impossível, interditado pela lei, cujos limites permanecem intransponíveis para todos, impedindo um momento de ruptura que suscite o autoquestionamento, a reflexão da crítica e novas formas de vida.

\section{Culpa, destino e direito}

A crítica de Benjamin sobre "As afinidades eletivas" é uma luta contra a cristalização da obra literária e um protesto contra sua mitifcação. A partir da ideia da crítica enquanto tarefa interminável, pretendemos suscitar novos olhares para o direito a partir do romance de Goethe. Isso implica não uma transposição imediata, não a retirada de uma lição que Goethe teria nos legado. Na verdade, pretende-se aqui exaltar a potência criativa da literatura para o direito. A importância de Benjamin para este trabalho se deve às suas reflexões sobre o direito, que se cruzam com suas reflexões sobre literatura. Seu texto sobre "As afinidades eletivas" é escrito entre 1919 e 1922, na mesma época que Destino e Caráter, de 1919, e Para uma Crítica da Violência, de 1921, que trazem contribuições para o mundo jurídico. A partir das categorias de culpa e destino, pretende-se investigar qual o papel delas no direito e quais novas problematizações podemos elaborar sobre a relação entre este e a sociedade.

Como foi dito acima, Mittler expõe o nexo entre lei e crime na tentativa mesma de obscurecê-la. Seu discurso não é a causa da morte de Ottilie, mas sua sentença. A menina não sucumbe pelo seu agir, mas pela sua inação, aceitando a culpa, indissociável da lei. É preciso uma análise mais adequada, a partir da seguinte pergunta: como pode a culpa estar na base da lei?

A lei só se faz necessária porque os indivíduos não agirão moralmente de forma necessária, conforme uma lei da causalidade, mas, uma vez que são seres livres, trazem consigo a possibilidade de agir em desconformidade com o dever. 
Dessa maneira, os indivíduos já seriam concebidos a partir do direito como aqueles que, naturalmente, não possuem condições de estabelecer uma convivência harmoniosa, uma vez que podem, a cada instante, conduzir-se por suas próprias inclinações, ameaçando a coexistência das liberdades externas. A lei é necessária na medida em que não é certo que o indivíduo se mantenha no dever, podendo agir por outros motivos. Certo apenas é o fato de que ele não conseguirá pagar seu débito perante a lei, jamais podendo acessá-la por completo. O descompasso inescapável entre o agir humano e a lei, que decorre da própria liberdade humana, é o que suscita a culpa que dá origem ao direito, sendo ela, portanto, pressuposta e dita natural.

De outro ponto de vista, seria não o mal no homem que acarretaria a culpa, mas o conhecimento do bem e do mal. O que há de mais condenável no homem é que, mesmo conhecendo a lei, ele a transgride. Portanto, não basta simplesmente que se enuncie a lei, mas que o indivíduo se sujeite à sua coercitividade. A culpa não decorre de um mal biologicamente identificado, pois aquilo que vem da natureza não poderia ser imputável. Na verdade, a culpa decorre de uma transgressão da lei que ocorre na medida em que o sujeito tem conhecimento dela. Sendo este o pressuposto, a culpa não advém de uma conduta fática, mas logo no nível da consciência, de uma lei que se torna uma autoridade internalizada, culpabilizando não simplesmente o agir, mas até mesmo reprimindo o mero desejo contrário à lei. Logo, a relação do Estado para com a sociedade só pode ser de constante desconfiança e vigilância. Isso estaria na base da lei moderna, que gradativamente torna cinzenta a linha que divide o criminoso do cidadão de bem:

A redução do homem à vida nua é hoje a tal ponto um fato consumado que
ela está agora na base da identidade que o Estado reconhece perante seus
cidadãos. Assim como o deportado de Auschwitz não tinha mais nome nem
nacionalidade e era a partir de então somente o número que havia sido
tatuado em seu braço, do mesmo modo o cidadão contemporâneo, perdido
na massa anônima e equiparado a um criminoso em potencial, não é
definido senão pelos dados biométricos e, em última instância, por uma
espécie de fado antigo tornado ainda mais opaco e incompreensível: o seu
DNA. (AGAMBEN, 2014, p. 84-85)

A culpa é o pressuposto da lei, mas além disso, ela reduz o homem à mera vida, tornando-se objeto, não mais sujeito, da lei. Sua identidade não se dá no 
espaço público com seus semelhantes, mas é delimitada pelos dispositivos do Estado. A necessidade de vigilância incessante e as mudanças na legislação penal, tornando-a cada vez mais rígida, só tornam explícito que o efeito da lei sobre o indivíduo não é simplesmente uma punição, mas a culpa. Diante da lei só há uma dívida infindável e a aceitação de que não é possível saldá-la devido a uma natureza corrompida. A vida culpada, então, emudece. Não há o que fazer perante a lei senão esperar e se deixar arrastar pelos seus ditames; não há o que dizer sobre o sofrimento que tais medidas acarretam senão que são um mal necessário e que é preciso esperar pelo progresso humano.

É nesse ciclo de violência que o mito expressa sua maior expressão: o sangue vertido. É este eterno retorno que faz com que a culpa não tenha expiação, sendo consequência da dívida infinita do homem perante a lei. O sofrimento de hoje não libera do sofrimento de amanhã, mas anuncia seu retorno. O que mais caracteriza a mera vida em Benjamin é a incapacidade de uma decisão, a vitória das forças do mito. O principal do agenciamento entre violência e vida natural é que ela mantém o indivíduo em uma roda de tortura e impede a decisão sobre a vida, restando apenas as escolhas entre as opções já postas, que como partem da culpa natural, só podem fornecer instrumentos de administração do sofrimento, dispositivos de controle e segurança.

O direito vive em função da culpa natural, esta é a base mítica que o legitima e o põe a servir de controle da vida humana, constituindo seu destino. Seu fortalecimento, inclusive, se dá na medida em que os indivíduos internalizam a culpa. Isso ocorre de maneira perversa. O fundamento do Estado, sua necessidade, reside na natureza violenta dos indivíduos, que precisam ser contidos, precisam ceder sua potência ao Estado. Quando alguém reafirma esse mito, muitas vezes não se refere a si próprio, mas a um significante vazio: "nós", "os humanos", "todo mundo", em frases como "sem o Estado, as pessoas cometerão arbitrariedades". Ou seja, a culpa não possui destinatário certo e ao mesmo tempo ela é universal. Isso traz consequências graves. Ainda que alguém se considere um homem de bem, ainda que ache que não precisa do Estado, este é justificado pela desconfiança com 
os outros. Assim, todo mundo pode se julgar inocente e terminar todo mundo culpado. O Estado vive dessa disseminação da culpa, da estratificação dos indivíduos e da desconfiança mútua entre as pessoas. É por isso que mesmo um cidadão de bem pode sofrer com uma arbitrariedade do Estado. Ele pode sofrer abuso de um policial, por exemplo, mesmo sendo inocente. Entretanto, logo surgirão discursos de justificação: "mas o policial precisa fiscalizar as pessoas, pois nunca sabemos o que esperar delas". Ou então uma pessoa pode efetivamente ser morta inocentemente, e logo alguém pode dizer: "se foi morto é porque fez algo de errado", "e o que ele estava fazendo naquele lugar, naquela hora?". O direito se fortalece com a culpa, mas esta sequer é localizável, mas espectral. Em última instância, essa violência mítica se baseia no vínculo entre destino e caráter. A culpa é o destino do caráter corrompido. A consequência mais grave da reprodução da culpa é que ela se fixa a um indivíduo, o que faz com que todas as tentativas de resolução dos problemas se resumam na procura do culpado. Esse vínculo torna impossível uma perspectiva sobre as relações que conferem forma a esse indivíduo e quais as forças que introduzem a culpa na sua vida. A violência mítica se alimenta desse vínculo para escapar de qualquer abordagem mais apurada, escondendo-se em um indivíduo, num bode expiatório (e caberia ainda questionar a função paradoxal do bode "expiatório", que apenas anuncia o sofrimento de amanhã).

Observamos que no romance a morte de Otto não é encarada como uma tragédia, mas incluída em um pretenso processo que levará as personagens a encontrar a solução para seus dilemas. Assim, como podemos abordar a invisibilidade do sofrimento perante o progresso? Haveria no mundo jurídico também a inércia dos indivíduos, no sentido paradoxal de um agir vazio e mecânico, na medida em que é mera sujeição, frente às catástrofes? Essa invisibilidade não remete apenas ao "não ver", mas à interpretação do sofrimento a partir de uma lógica ambígua. As mortes produzidas em nome do progresso humano causam impacto e podem até entristecer, mas no final das contas, toma-se o evento como um mal necessário, como algo que, apesar de triste, trará grandes conquistas e aprendizados. Essa ambiguidade também pode ser notada no papel da polícia: ela é apresentada como protetora da sociedade, mas precisa eliminar partes dessa 
sociedade, salvá-la dela mesma. Todo assassinato causado pelo aparato policial do Estado é reconduzida aos termos de um plano maior. É preciso matar hoje para não matar amanhã. Entretanto, o perigo está na totalidade falsa que tal lógica engendra, pois, de maneira dúbia, o sacrifício de hoje não traz redenção para o amanhã, mas anuncia outro sacrifício. O semblante do mito petrifica a crítica, neutralizando-a devido à sua natureza ambígua: apresenta-se como uma solução, mas é sempre adiada. Como diz Goethe, a esperança acaba por produzir uma insensibilidade:

Felizmente, o ser humano é capaz de conceber o infortúnio só até certo grau; o excedente aniquila-o ou deixa-o indiferente. Há situações nas quais 0 temor e a esperança confundem-se, anulam-se reciprocamente e se perdem numa obscura insensibilidade. (GOETHE, 2008, p. 127)

É nesse ciclo de sacrifícios que o direito se vê preso, tendo como motor viciado uma violência mítica que, sob o signo do progresso, não cessa de se repetir. Geralmente entendemos o catastrófico como algum evento que irrompe de maneira brusca no cotidiano. A partir de Benjamin, no entanto, como explica Reyes Mate, é a eternização de uma história de sofrimentos que caracteriza a catástrofe: "o catastrófico é a eternização do que já temos, a irreversibilidade do curso que nos trouxe até aqui. $O$ angustiante não é que a história tenha um fim, mas que não o tenha" (MATE, 2011, p. 214).

O aspecto mítico do direito possui uma ambiguidade: ilumina o caminho para a resolução dos problemas da sociedade, mas ao mesmo tempo constitui-se como único caminho possível. Assim, todo o problema da segurança pública e, de maneira mais geral, da relação entre Estado e sociedade só se dá enquanto localização de disfunções. A força mítica do direito implica que este nunca seja questionado, sendo qualquer catástrofe a consequência de um mau uso do direito, não de uma lógica interna, e isso implica necessariamente apontar alguns culpados. Do agente público corrupto ao gestor incompetente, todo questionamento parte da inevitável concepção de Estado enquanto ente regulador de indivíduos facilmente capturados pelos impulsos mais animalescos junto à crença na sua capacidade de resolução de conflitos para a indicação daqueles que estão impedindo que ele funcione bem. Questionar o direito penal, por exemplo, torna-se não uma questão de fundamento, mas de eficiência, e por isso temos um único foco de investigação: como endurecer 
o sistema penal. Uma crítica deste tipo é impotente na medida em que ataca apenas "leis ou práticas de direito isoladas, que o direito protegerá com seu poder [Macht], o qual reside no fato de que só existe um único destino e que justamente aquilo que existe, e em particular aquilo que ameaça, pertence inexoravelmente à sua ordem"(BENJAMIN, 2011, p. 133). Tal como as personagens de "As afinidades eletivas", os juristas, diante de uma realidade que só apresenta excessos, podem apenas escolher entre as opções tornadas possíveis pela base mítica do mundo jurídico, normalizando os fenômenos mais drásticos. Assim, o Estado deixa de ser a reunião de indivíduos preocupados em organizar a vida em sociedade para ser um instrumento de controle da desordem. Diante de uma realidade que já mostra a violência em seus extremos, o papel do Estado cada vez mais é administrar esses extremos, paradoxalmente mantê-los dentro do controle (e fora de qualquer questionamento), ao invés de interromper o ciclo que perpetua essa violência.

No romance, a situação de Charlotte e do Major permanece em suspensão. Após a morte de Ottilie e Eduard, não sabemos se eles continuarão participando da culpa ou se vão iniciar um relacionamento. É preciso notar que se a catástrofe é signo do destino e que ele não expia a culpa, mas a transmite, ela é também o momento para o autoquestionamento, quando a promessa garantida pelo direito se mostra frágil. É o momento para, ou reconduzi-la à conta do progresso, ou interromper o ciclo de violência.

Como apontar, no entanto, para essa decisão que consegue se livrar da violência mítica do direito? Em "As afinidades eletivas", Goethe insere no meio do romance uma pequena novela, em que dois vizinhos decidem, contra tudo e contra todos, ficar juntos, rompendo com o destino que havia sido imposto a eles. Esta novela, no entanto, não pôde ser aprofundada aqui, sendo necessário um outro trabalho, com a devida atenção, para uma análise mais apurada.

\section{Conclusão}


As personagens de "As afinidades eletivas" são vencidas pelas forças do mito. O vínculo jurídico do casamento, transformado em mero símbolo e imperativo, constitui o limite de suas vidas. A violência mítica do direito é primordialmente uma interdição, e a sujeição vazia à sua lei se torna necessária devido a uma culpa natural. O núcleo da lei, que não pode ser questionado, determina as fronteiras da vida, que acaba enclausurada, e a dificuldade de suscitar o divórcio no romance evidencia isso. Não é possível decidir sobre a própria vida, mas apenas circular entre as escolhas definidas pela lei. Não é possível decidir pelo presente, mas sempre adiar a resolução dos problemas. Sem a possibilidade do desvio, a trajetória das personagens é uma linha reta com destino certo: a catástrofe.

De maneira mais geral, a crença na capacidade do direito de resolver os problemas da sociedade também constitui um limite, sendo tais problemas infinitamente reconduzidos à lei. As soluções propostas não rompem com um estado de coisas, mas o aprofundam, na medida em que lidam apenas com problemas de eficiência. Elas têm como escopo apenas aumentar o âmbito de incidência da lei e sua intensidade. No mundo jurídico, à falta de espanto do operador do direito quanto à distância abissal entre as declarações de direitos fundamentais e os problemas atuais, e à crença na promessa do ordenamento jurídico de garantir o futuro, sucede necessariamente a incapacidade de pensar os elos que mantêm essa promessa irresoluta. Diante disso, as crises ganham o tom da catástrofe e as respostas aos desafios presentes vêm ao mundo natimortas: se a promessa de ontem não se cumpriu, faz-se mais uma no dia de hoje; se a lei de ontem não efetivou direitos, cria-se mais leis; se os tratados assinados não garantiram a paz, assina-se mais tratados. É no adiamento e na hesitação, tal como ocorre no romance de Goethe, que os indivíduos rumam cegamente à tragédia. A medida que propõe um enrijecimento dos dispositivos de segurança e de normas penais se coloca apenas como uma preparação para uma medida ainda mais rígida, que deverá ser tomada depois.

Nesse círculo vicioso, todas as mortes são interpretadas como um mal necessário, um preço a se pagar pelo futuro em que será possível a plenitude de 
direitos. A realidade é naturalizada, tomada como um destino, tal como expressa a frase de Goethe, citada por Benjamin: "vocês permitiram aos pobres tornarem-se culpados" (BENJAMIN, 2011, p. 94). A culpa do pobre decorre de ele sempre estar devendo sua força de trabalho à sociedade.

A sujeição muda e culpada de todos os indivíduos a essa lógica perversa, a aceitação de sua dívida infinita para com a lei, apenas alimenta o ciclo de violência. Todo sofrimento é visto como um sacrifício necessário para acessar uma lei que se coloca como inacessível, para saldar um débito que é infinito, não havendo nada a ser feito a não ser esperar por progresso que é sempre mais uma vez adiado. Como a culpa e a desconfiança são disseminadas na sociedade, cada indivíduo é um criminoso em potencial, não havendo ninguém que possa se elevar sobre esse ciclo de violência, que se mostra uma roda de tortura que traz como característica essencial verter sangue.

Neste trabalho, aproximamos o romance de Goethe com o direito para explicitar o núcleo mítico do direito, que se alimenta de uma culpa natural imposta aos indivíduos, que são condenados numa roda de tortura, num ciclo de violência em que cada sacrifício não oferece redenção, mas a repetição do mesmo. A tarefa do crítico se impõe como uma atitude perante a catástrofe que, ao invés de relativizá-la e naturalizá-la, visa à interrupção do ciclo de violência, impedindo sua repetição e fazendo emergir novas formas de vida.

\section{REFERÊNCIAS}

AGAMBEN, Giorgio. Nudez. Tradução Davi Pessoa Carneiro. 1 ed. Belo Horizonte: Autêntica Editora, 2014.

BENJAMIN, Walter. Ensaios reunidos escritos sobre Goethe. Tradução Mônica Krausz Bornebusch, Irene Avon e Sidney Camargo. São Paulo: Duas Cidades; Ed. 34, 2009. 
. Escritos sobre mito e linguagem (1915-1921). Tradução Susana Kampff

Lages e Ernani Chaves. São Paulo: Duas Cidades; Ed. 34, 2011.

. O anjo da história. Tradução João Barrento. Belo Horizonte: Autêntica

Editora, 2012.

CASTRO, Claudia. A alquimia da crítica: Benjamin e As afinidades eletivas de Goethe. Rio de Janeiro: Paz e Terra, 2011.

GAGNEBIN, Jeanne Marie. Limiar, aura e rememoração: ensaios sobre Walter Benjamin. São Paulo: Editora 34, 2014.

GOETHE, Johann Wolfgang Von. As afinidades eletivas. Tradução Erlon José Paschoal. São Paulo: Nova Alexandria, 2008.

LEACOCK, N. K. Character, silence and the novel: Walter Benjamin on Goethe's Elective Affinities. Narrative, Volume 10, Number 3, 2002.

MATE, Reyes. Meia-noite da história: comentários às teses de Walter Benjamin “Sobre o conceito de história”. Tradução Nélio Schneider. São Leopoldo, RS: Ed. UNISINOS, 2011. 